\title{
Digestibilidade dos nutrientes de alimentos volumosos determinada pela técnica dos sacos móveis em eqüinos ${ }^{1}$
}

\author{
Vinícius Pimentel Silva ${ }^{2}$, Fernando Queiroz de Almeida ${ }^{3}$, Eliane da Silva Morgado², Almira \\ Biazon França ${ }^{4}$, Henrique Torres Ventura ${ }^{5}$, Liziana Maria Rodrigues ${ }^{4}$
}

\author{
${ }^{1}$ Projeto financiado pelo CNPq. \\ 2 Mestrando em Zootecnia - UFRRJ. Bolsista CAPES \\ 3 Instituto de Veterinária - UFRRJ. Bolsista Pesquisador CNPq. \\ ${ }^{4}$ Graduação em Zootecnia - UFRRJ. Bolsista de Iniciação Científica PIBIC-CNPq/UFRRJ. \\ ${ }^{5}$ Graduação em Zootecnia - UFRRJ. Bolsista de Iniciação Científica FAPERJ.
}

RESUMO - Objetivou-se estimar a digestibilidade de nutrientes de forrageiras em eqüinos utilizando-se a técnica de sacos de náilon móveis. Foram avaliados alfafa (Medicago sativa), amendoim forrageiro (Arachis pintoi), desmódio (Desmodium ovalifolium), estilosantes (Stylosanthes guianensis), guandu (Cajanus cajan), macrotiloma (Macrotyloma axillare) e capimcoastcross (Cynodon dactylon cv. coastcross). O delineamento foi em blocos inteiramente casualizados com sete alimentos e cinco blocos (animais). Foram utilizados cinco eqüinos mestiços com 17 a 27 anos de idade e peso vivo médio de $350 \mathrm{~kg}$. O ensaio teve duração de 12 dias: três para a adaptação às baias, cinco para inserção gástrica dos sacos através de sonda nasogástrica e quatro de coleta dos sacos nas fezes. No período pré-experimental de 30 dias, os animais foram mantidos em piquetes com dieta composta de $80 \%$ de feno de coastcross e $20 \%$ de concentrado. Na confecção dos sacos, utilizou-se náilon com porosidade de $45 \mu$ e dimensão de 7,5 $\times 2 \mathrm{~cm}$. Em cada saco, foram inseridos $510 \mathrm{mg}$ de matéria seca de amostra do alimento Os coeficientes de digestibilidade dos nutrientes das forragens foram calculados considerando o resíduo obtido no saco. A digestibilidade dos nutrientes do amendoim, estilosantes e macrotiloma foram superiores à da demais forrageiras, com destaque para a digestibilidade da proteína bruta, cujos valores foram de 91,4; 94,9 e 97,0\%, respectivamente. O amendoim e macrotiloma apresentaram digestibilidade da fibra em detergente neutro de 72,3 e $65,2 \%$ e da fibra em detergente ácido de 70,9 e $59,4 \%$, respectivamente. $\mathrm{O}$ amendoim forrageiro, macrotiloma e estilosantes apresentam digestibilidade dos nutrientes satisfatória e têm potencial para o uso em dietas para eqüinos.

Palavras-chave: cavalos, digestão, fibra, forragem

\section{Nutrient digestibility of forage feed determined using mobile bag technique in horses}

\begin{abstract}
This work was carried out to evaluate the nutrient digestibility of forages using mobile bags technique in horses. The forages were lucerne (Medicago sativa), peanut (Arachis pintoi), desmodio (Desmodium ovalifolium), stylo (Stylosanthes guianensis), pigeon pea (Cajanus cajan), lime-yellow pea (Macrotyloma axillare) and coastcross (Cynodon dactylon $c v$. coastcross). A randomized block design was used with seven treatments (feeds) and five blocks (horses). Five crossbreed horses were used with age ranging from 17 to 27 years and average weight of $350 \mathrm{~kg}$. The assay lasted 12 days, being three days for adaptation to barns, five days for nasogastric insertion of bags and four days for bags collection in feces The diet of horses was composed of $80 \%$ of coastcross hay and $20 \%$ of commercial concentrate. During the pre-experimental period of 30 days, the horses were maintained in paddocks feeding the diet. Nylon cloth had $45 \mu$ pore size, and bags presented dimensions of $7,5 \times 2 \mathrm{~cm}$ with $510 \mathrm{mg}$ of DM of forage sample/bag. The nutrient digestibility of forages were calculated through residues inside the bags. The nutrient digestibility of peanut, stylo and lime-yellow pea were high than the other forages, mainly crude protein with values of 91.4, 94.9 and 97.0\%, respectively. Fibrous fractions of peanut and lime-yellow pea presented digestibility values of NDF of 72.3 and $65,2 \%$, and ADF of 70.9 and $59.4 \%$, respectively. Peanut, lime-yellow pea and stylo presented satisfactory nutrient digestibility and had potential to use in diets for horses.
\end{abstract}

Key Words: digestion, fiber, forage, horses 


\section{Introdução}

A determinação da composição químico-bromatológica e da digestibilidade dos nutrientes de forrageiras utilizadas em dietas para eqüinos permite caracterizar a qualidade dos alimentos. Infelizmente, a escassez de informações nutricionais referentes aos volumosos destinados à espécie eqüina resulta na elaboração de dietas com alimentos de países de clima temperado, segundo estimativas e tradições desses países.

Segundo Cunha (1980), quanto maior a atividade física do cavalo, maior a sua demanda energética e, desta forma, o percentual de alimentos volumosos será menor em relação ao concentrado nas dietas. Esse fato indica a importância da qualidade do volumoso, em decorrência da maior disponibilidade de energia, pois parte da energia dietética absorvida pelos animais é proveniente da energia dos ácidos graxos voláteis produzidos pela fermentação intestinal. Há ainda a inquestionável importância de forragens para o funcionamento normal do trato digestivo (Moore-Colyer et al., 2003) e da prevenção dos distúrbios comportamentais decorrentes da redução dos níveis de fibra na dieta (Pagan, 2001).

Hintz (1989) observou que vários alimentos podem ser utilizados como fonte de fibra na alimentação de eqüinos e que o valor energético pode auxiliar na avaliação econômica da substituição de um alimento volumoso por outro. O NRC (1989) sugeriu que a leguminosa Arachis sp. apresenta potencial para fenação, entretanto, não fez ressalvas quanto à espécie vegetal e seu consumo.

O conhecimento do valor nutricional de um alimento é imprescindível para estimativa da digestibilidade de seus nutrientes, e o processo normalmente utilizado consiste em medir diretamente o consumo e a excreção fecal durante certo período (Pereira et al., 1995). Portanto, para o uso correto dos alimentos nas dietas, são necessários estudos específicos para determinação da digestibilidade e do valor nutricional dos alimentos em potencial. A coleta total de fezes é a metodologia mais precisa, porém tem limitações, como o número de animais, estudo de apenas um alimento por ensaio, tempo de adaptação à dieta, alto custo das gaiolas para estudos do metabolismo, grande volume de fezes, entre outros.

$\mathrm{Na}$ impossibilidade de utilização de dietas exclusivas de um alimento volumoso alternativo, o que também não reflete a realidade na alimentação da espécie, os sacos móveis têm a vantagem de permitir a avaliação de vários alimentos simultaneamente. A técnica é um método in vivo que consiste na utilização de pequena quantidade de alimento em sacos que são inseridos no trato digestivo através de uma cânula ou diretamente no estômago através de sonda nasogástrica, permitindo que os sacos atravessem todo o trato digestivo e sejam depois recuperados nas fezes (Hyslop, 2006). Esta técnica foi inicialmente utilizada em suínos (Sauer et al., 1983), depois em ruminantes e então adaptada para eqüinos (Araújo et al., 1996ab; Macheboeuf et al., 2003; Hyslop, 2006).

Neste trabalho avaliou-se a digestibilidade de nutrientes, pela técnica dos sacos móveis de forragens usuais e outras com potencial para uso em dietas para eqüinos.

\section{Material e Métodos}

O ensaio foi conduzido no Laboratório de Pesquisas em Saúde Eqüina - EQUILAB do Instituto de Veterinária da Universidade Federal Rural do Rio de Janeiro. As análises laboratoriais foram realizadas no EQUILAB e no Laboratório de Bromatologia do Departamento de Nutrição Animal e Pastagens do Instituto de Zootecnia da UFRRJ.

O delineamento experimental foi o de blocos casualizados, composto de sete alimentos e cinco animais, segundo o modelo estatístico: $y i j=m+b j+t i+e i j$, em que: $y_{i j}=$ valor da característica estudada no alimento $\mathrm{i}(\mathrm{i}=1$, $2, \ldots, \mathrm{I})$, no animal $\mathrm{j}(\mathrm{j}=1,2, \ldots \mathrm{J}) ; m=$ média geral do experimento; $b_{j}=$ efeito do animal; $t_{i}=$ efeito do alimento; $e_{i j}=$ erro associado à observação $y i j$ na repetição $\mathrm{j}$, ou efeito dos fatores não controlados sobre a observação $y_{i j}$.

Utilizaram-se cinco eqüinos machos adultos, com idade variando de 17 a 27 anos, castrados, sem raça definida, com peso corporal de $350 \pm 28 \mathrm{~kg}$, imunizados contra tétano, vermifugados e pulverizados contra ectoparasitos. Os animais foram mantidos em baias individuais, com piso de cimento, providas de bebedouros e comedouros específicos para eqüinos, com livre acesso a água. Foram pesados antes do início do período experimental para ajuste da dieta em relação ao peso corporal.

No período pré-experimental, com duração de 30 dias, os animais foram alimentados com dieta composta de $80 \%$ de volumoso, na forma de feno de capim coastcross (Cynodon dactylon cv. coastcross) e 20\% de concentrado comercial (Tabela 1).

A dieta foi fornecida aos animais considerando o consumo diário individual de $2,0 \%$ do peso vivo, na matéria seca, de acordo com as recomendações do NRC (1989), referentes às exigências diárias para eqüinos de $400 \mathrm{~kg}$. Durante a condução do ensaio, a dieta foi fornecida às 1 , 7, 13 e $19 \mathrm{~h}$, em quantidades iguais.

Foram avaliados os alimentos volumosos: alfafa (Medicago sativa), amendoim forrageiro (Arachis pintoi 
cv. Amarillo), desmódio (Desmodium ovalifolium), estilosantes (Stylosanthes guianensis cv. Mineirão), guandu (Cajanus cajan), macrotiloma (Macrotyloma axillare) e feno de capim coastcross (Cynodon dactylon cv. coastcross) (Tabela 2). A coleta das amostras das leguminosas amendoim forrageiro, desmódio, estilosantes, guandu e o macrotiloma foi realizada nos canteiros do Departamento de Nutrição Animal e Pastagens, entre os meses de janeiro e março de 2006, com idades de corte de 60 a 90 dias, enquanto as amostras do feno de capim- coastcross e do feno de alfafa foram adquiridas no comércio local.

O experimento teve duração de 12 dias, três para a adaptação as instalações, cinco dias para administração dos sacos de náilon pela sonda nasogástrica e quatro dias de coleta de sacos nas fezes. Os sacos foram preparados com dimensões de 7,5 $\times 2 \mathrm{~cm}$, utilizando-se tecido de poliéster de porosidade de $45 \mu$ (Tenyl $\left.{ }^{\circledR}\right)$, selados a quente e preparados conforme descrito por Araújo et al. (1996ab). Os sacos foram identificados com caneta Pilot ${ }^{\circledR}$ e, em seguida, colocados em estufa de ventilação forçada a $55-60^{\circ} \mathrm{C}$ por 24 horas, retirados e colocados em dessecador e, posteriormente pesados. As amostras de alimento foram trituradas em moinho martelo com peneira de malha de $2 \mathrm{~mm}$.

Em cada saco colocou-se uma quantidade de amostra de $17 \mathrm{mg} \mathrm{MS} / \mathrm{cm}^{2}$ de superfície. Segundo Vanzant et al.

Tabela 1 - Composição bromatológica do feno de coastcross e do concentrado, em porcentagem da matéria seca

\begin{tabular}{lcc}
\hline Composição & Feno de coastcross & Concentrado \\
\hline Matéria seca (\%) & 88,4 & 88,7 \\
Matéria orgânica (\%) & 93,8 & 82,8 \\
Proteína bruta (\%) & 11,9 & 11,1 \\
Extrato etéreo (\%) & 1,3 & 3,7 \\
Fibra em detergente neutro (\%) & 67,2 & 44,8 \\
Fibra em detergente ácido (\%) & 31,4 & 18,4 \\
Celulose (\%) & 2,4 & 1,6 \\
Energia bruta (Mcal/kg) & 3,49 & 3,45 \\
\hline
\end{tabular}

Valores médios determinados por análise bromatológica.
(1998), a relação quantidade de amostra $(\mathrm{mg}) /$ área $\left(\mathrm{cm}^{2}\right)$ foi estabelecida entre 10 a $20 \mathrm{mg} / \mathrm{cm}^{2}$, de acordo com a fórmula: $\operatorname{amostra}(\mathrm{mg})=$ comprimento $(\mathrm{cm}) \times \operatorname{largura}(\mathrm{cm})$ $\times 2$. A área total do saco foi igual a $30 \mathrm{~cm}^{2}$, com capacidade para $510 \mathrm{mg}$ de amostra/saco.

A inserção dos sacos no estômago dos cavalos foi realizada com o auxílio de sonda nasogástrica semisiliconizada, de $15 \mathrm{~mm}$ de diâmetro interno, lubrificada externamente com vaselina líquida. A sonda foi utilizada às 7 e $19 \mathrm{~h}$, durante cinco dias. A inserção gástrica dos sacos iniciou-se 24 horas antes do primeiro dia de coleta dos sacos nas fezes, totalizando dez sondagens para cada animal durante o período experimental.

Em cada sondagem, foram utilizados quatro sacos com amostras de cada alimento e um saco sem amostra, totalizando 29 sacos em cada sondagem/animal. Todos os sacos foram previamente inseridos na sonda antes da passagem nos animais com o auxílio de um êmbolo. Após a inserção nasogástrica, foram introduzidos aproximadamente 750 a $1.000 \mathrm{~mL}$ de água, sob pressão, na luz da sonda para facilitar a passagem dos sacos para o estômago (Moore-Colyer et al., 2002).

Realizou-se um ensaio preliminar para definir qual o tempo para início da coleta dos sacos nas fezes. Foram utilizados dois animais, nos quais foram inseridos às $7 \mathrm{~h}$, 29 sacos preparados de acordo com o protocolo descrito acima. Observou-se o momento inicial de aparecimento dos sacos nas fezes, definindo-se que, durante o período experimental, a coleta dos sacos teria início 18 horas após a inserção.

A coleta de fezes foi realizada diariamente durante quatro dias. Os sacos foram retirados imediatamente após a excreção das fezes e foram considerados somente aqueles recuperados até 96 horas após a inserção gástrica (Araújo et al., 1996ab). Após a recuperação dos sacos, anotou-se o horário de excreção e então os sacos foram armazenados a $-18^{\circ} \mathrm{C}$. Ao final de cada dia de coleta, os sacos foram descongelados e lavados com água fria em máquina de lavar. Na lavagem

Tabela 2 - Composição bromatológica dos alimentos, em porcentagem da matéria seca

\begin{tabular}{|c|c|c|c|c|c|c|c|}
\hline Composição ${ }^{1}$ & Alfafa & Amendoim & Desmódio & Estilosantes & Guandu & Macrotiloma & Coastcross \\
\hline Matéria seca (\%) & 88,9 & 24,5 & 30,9 & 33,1 & 34,8 & 17,2 & 85,9 \\
\hline Matéria orgânica (\%) & 91,6 & 92,1 & 94,9 & 93,8 & 95,6 & 94,4 & 95,1 \\
\hline Proteína bruta $(\%)$ & 17,6 & 18 & 14 & 16,2 & 20,3 & 19,1 & 6,3 \\
\hline Extrato etéreo (\%) & 1,4 & 1,9 & 2,6 & 5,6 & 4,1 & 2,1 & 1,5 \\
\hline Fibra em detergente neutro $(\%)$ & 64,5 & 46,8 & 52,5 & 47,5 & 56,9 & 38,2 & 82,9 \\
\hline Fibra em detergente ácido (\%) & 43,7 & 30,7 & 32,9 & 33,3 & 28,5 & 26,3 & 39,8 \\
\hline Celulose $(\%)$ & 30,7 & 18,7 & 23,4 & 23,4 & 15,5 & 18,9 & 16,1 \\
\hline Lignina $(\%)$ & 8,3 & 12,4 & 8,9 & 9,6 & 12,6 & 7,4 & 4 \\
\hline Energia bruta (Mcal/kg) & 3,92 & 3,9 & 4,36 & 4,36 & 4,52 & 4,27 & 3,93 \\
\hline
\end{tabular}

\footnotetext{
${ }^{1}$ Valores médios determinados por análise bromatológica.
} 
dos sacos, utilizou-se um saco protetor onde foram inseridos, em média, 25 sacos. O tempo de lavagem utilizado foi de 15 minutos (Macheboeuf et al., 2003).

Os sacos foram secos em estufa ventilada a $55-60^{\circ} \mathrm{C}$, durante 48 horas. Após a secagem, cada saco foi pesado para determinação das perdas de matéria seca. Uma amostra composta de cada alimento foi formada a partir dos sacos recuperados de cada animal. Os sacos sem amostra foram utilizados para determinar as impregnações e posterior correção da digestibilidade dos nutrientes.

As perdas dos nutrientes foram expressas como coeficiente de digestibilidade da matéria seca, matéria orgânica, proteína bruta, energia bruta, fibra em detergente neutro e fibra em detergente ácido, determinadas pelo resíduo de amostra composta e calculadas com a equação: $C D(\%)=((I-F) / I) \times 100$, em que: $I=$ quantidade de alimento $(\mathrm{mg})$ inserida em cada saco; e $\mathrm{F}=$ resíduo do alimento $(\mathrm{mg})$ após a recuperação dos sacos nas fezes (Moore-Colyer et al., 2002).

As análises das amostras foram feitas para determinação dos teores de matéria seca (MS), proteína bruta (PB), extrato etéreo (EE), energia bruta (EB), matéria mineral $(\mathrm{MM})$, fibra em detergente neutro (FDN), fibra em detergente ácido (FDA), celulose (CEL) e lignina (LIG), segundo metodologia descrita por Silva \& Queiroz (2002).

Os valores médios dos coeficientes de digestibilidade aparente dos nutrientes e da taxa de recuperação dos sacos de náilon foram submetidos à análise de variância e os valores médios comparados pelo teste Tukey, a 5\% de probabilidade, utilizando-se o programa o SAEG - Sistema de Análises Estatísticas e Genéticas (UFV, 2000).

\section{Resultados e Discussão}

A digestibilidade de matéria seca da alfafa foi de $63,5 \%$ (Tabela 3), similar ao valor médio observado por Almeida (1994), de 62,5\%, em compilação de inúmeros valores obtidos em ensaios de digestão com eqüinos constantes na literatura. No entanto, o valor observado foi superior ao citado por Almeida et al. (1999), de 55,2\% em ensaio de coleta total de fezes.

Pagan (2001), avaliando a alfafa em dietas de eqüinos e utilizando a coleta total de fezes, observou valor de $65,9 \%$ quando a planta estava jovem e de $56,0 \%$ no corte mais tardio. Portanto, a estimativa da digestibilidade da matéria seca pela técnica de sacos móveis foi satisfatória.

Em estudo desenvolvido com pôneis, Todd et al. (1995) avaliaram a digestibilidade do feno de alfafa com tipos de processamento e observaram digestibilidades médias de $61,9 \%$ da matéria seca e $78,2 \%$ da proteína bruta, contudo, o valor de $37,4 \%$ de digestibilidade da FDN foi inferior ao observado neste estudo, de $47,8 \%$, que pode ter ocorrido por interferência da técnica, superestimando a digestibilidade da fração fibrosa.

Os valores médios, mínimos e máximos do coeficiente de digestibilidade da fibra em detergente ácido da alfafa observados por Almeida (1994) foram de 37,5, 12,8 e 67,5\%, respectivamente, resultados com grande dispersão, na qual se encontra o valor da digestibilidade de FDA observado neste estudo, de $42,3 \%$. Almeida et al. (1999) estimaram o coeficiente de digestibilidade da FDA da alfafa em 32,9\% em eqüinos em ensaio de digestão com coleta total de fezes e, o NRC (2007) cita o coeficiente de digestibilidade da FDA da alfafa de $32,8 \%$. Esses valores sugerem que a técnica de sacos de náilon móveis superestimou a digestibilidade da fração fibrosa, principalmente FDA. Provavelmente parte desse material perdeu-se pela passagem direta pelos poros, principalmente durante a lavagem.

Segundo o NRC (1989), variedades da espécie Arachis sp. têm potencial para fenação, no entanto, não há detalhes sobre a composição química e a digestibilidade dos nutrientes dessas espécies. A dúvida quanto à sua utilização e qualidade nutricional na espécie eqüina ainda persistiu no NRC (2007), que não apresentou novas informações sobre a forrageira.

$\mathrm{O}$ amendoim forrageiro destaca-se entre as leguminosas tropicais por sua qualidade, no entanto, resultados foram obtidos com ruminantes, e assim, pouco se conhece sobre o potencial do amendoim forrageiro na alimentação da espécie eqüina.

A composição química do amendoim forrageiro deste estudo foi similar à observada por Ladeira et al. (2002a) e Valadares Filho et al. (2006). Os melhores valores de digestibilidade dos nutrientes foram observados para o amendoim forrageiro $(\mathrm{P}<0,05)$. E, apesar da presença de $12,4 \%$ de lignina na matéria seca, a digestibilidade das frações fibrosas foi satisfatória, com valores de $72,3 \%$ e $70,9 \%$ para FDN e FDA, respectivamente, o que está relacionado ao fato de que a deposição da lignina, principalmente nas folhas das leguminosas, difere das gramíneas, conseqüentemente, apresentou menor interferência na digestão da celulose e hemicelulose (Jung, 1984).

O desmódio apresentou digestibilidade da proteína bruta de $77,9 \%$ e conteúdo de $14 \%$ de PB. A qualidade nutricional desta leguminosa está relacionada aos altos teores de taninos, muitas vezes acima de $7 \%$, o que sugere inibição da atividade das enzimas celulases (Dall'Agnoll \& Scheffer-Basso, 2004), fato que possivelmente influenciou 
Tabela 3 - Digestibilidade de nutrientes dos volumosos

\begin{tabular}{|c|c|c|c|c|c|c|c|c|}
\hline Item & \multicolumn{7}{|c|}{ Coeficiente de digestibilidade (\%) } & $\mathrm{CV}(\%)$ \\
\hline MS & $63,5 \mathrm{c}$ & $83,7 \mathrm{a}$ & $64,5 \mathrm{c}$ & $75,6 b$ & $52,9 d$ & $82,9 a$ & $52,5 \mathrm{~d}$ & 1,1 \\
\hline РB & $77,4 \mathrm{~d}$ & $91,4 \mathrm{c}$ & $77,9 \mathrm{~d}$ & $94,9 \mathrm{~b}$ & $52,8 \mathrm{f}$ & $97,0 \mathrm{a}$ & $69,8 \mathrm{e}$ & 0,6 \\
\hline EB & $61,0 \mathrm{~d}$ & $69,3 \mathrm{c}$ & $69,2 \mathrm{c}$ & $75,6 b$ & $48,3 \mathrm{e}$ & $82,6 a$ & $48,8 \mathrm{e}$ & 1,2 \\
\hline FDN & $47,8 \mathrm{~d}$ & $72,3 \mathrm{a}$ & $43,7 \mathrm{e}$ & $53,3 \mathrm{c}$ & $37,3 \mathrm{f}$ & $65,2 \mathrm{~b}$ & $47,5 \mathrm{~d}$ & 2,4 \\
\hline
\end{tabular}

Médias seguidas de letras diferentes nas linhas diferem $(\mathrm{P}<0,05)$ entre si pelo teste Tukey.

a digestibilidade da fração fibrosa, com coeficiente de digestibilidade da FDN de 43,7\%.

Neste estudo o valor nutricional do estilosantes foi superior aos observados por Andrade (1981) e Ladeira et al. (2002b) e as diferenças podem ser explicadas pelo tipo de amostra utilizada no ensaio de digestão, colhidas em canteiros adubados e em idade de corte mais jovem. Além disso, o teor de extrato etéreo de $5,6 \%$ pode ter levado aos valores de digestibilidade da energia bruta de $75,6 \%$. O estilosantes foi uma das forrageiras com melhor digestibilidade, principalmente da PB, FDN e FDA com valores de 94,9; 53,3 e $53,5 \%$, respectivamente. Ladeira et al. (2002b), avaliando o valor nutricional do estilosantes, observaram elevados teores de lisina, metionina e treonina, de 0,63 e 1,04 e $0,39 \%$, respectivamente. Isto reflete o potencial nutricional da leguminosa no sistema de produção de eqüinos, principalmente nas categorias de animais em crescimento.

O guandu, apesar dos elevados conteúdos de PB, de $20,3 \%$, foi a leguminosa com menor digestibilidade protéica, de $52,8 \%$. Neste ensaio não se quantificou o nitrogênio insolúvel em detergente ácido (NIDA), contudo, segundo Valadares Filho et al. (2006), o conteúdo de proteína insolúvel em detergente ácido do guandu foi de 26,7\%, o que esclarece a baixa digestibilidade protéica observada.

A amostra de guandu utilizada no ensaio de digestão foi coletada de plantas adultas e, continha caule, pecíolo e limbo foliar. De acordo com Fukushima (2007), a deposição de lignina na parede celular aumenta conforme as plantas amadurecem, o que determina inversão da relação folha:caule, bem como maiores concentrações de lignina no caule em relação à folha. Esse mesmo autor ressalta que a lignina do caule pode ser diferente daquela presente nas folhas. Neste aspecto, a redução da digestibilidade da fração fibrosa do guandu pode ser explicada, pois parte da lignina do guandu, de $12,6 \%$, foi proveniente dos caules e das hastes, que apresentam menor digestibilidade da FDN e FDA, de 37,3 e 14,7\%, respectivamente.

De forma similar, o amendoim forrageiro apresentou $12,4 \%$ de lignina na matéria seca, contudo, a quantidade de folhas na amostra utilizada no ensaio foi maior, e a lignina no amendoim forrageiro teve menor influência sobre a digestibilidade da fração fibrosa em comparação ao guandu. Segundo Jung \& Allen (1995), as folhas das leguminosas não apresentam aumento da parede celular, em decorrência da maturação. Além disso, a lignina das folhas pode diferir daquela presente nos caules (Fukushima, 2007).

Apesar dos baixos valores de digestibilidade dos nutrientes do guandu observados neste trabalho, outros autores observaram resultados satisfatórios com a utilização do guandu adicionado às dietas. Manzano et al. (1990) sugeriram que a utilização do guandu como parte do volumoso em dietas para eqüinos em níveis de 10 a $20 \%$ da matéria seca não alterou a digestibilidade. Ferreira et al. (1995), em ensaio de digestão com eqüinos consumindo dieta volumosa composta de capim-elefante e feno de guandu, concluíram que a inclusão de até $30 \%$ de feno de guandu na dieta proporcionou maior consumo voluntário de matéria seca, melhores coeficientes de digestibilidade dos nutrientes $\mathrm{e}$ atendeu às exigências energéticas $\mathrm{e}$ protéicas de eqüinos em mantença.

O conteúdo protéico do macrotiloma foi similar aos observados por Alcântara \& Bufarah (1988). Mais recentemente, Pádua et al. (2006) avaliaram o potencial do Macrotyloma axillar e para fenação e citaram os valores médios na composição do feno de $15,4 \%$ de PB, 50,4\% de FDN e 39,3\% de FDA. Esses valores indicam potencial da leguminosa, como observado neste trabalho, com valores elevados para os coeficientes de digestibilidade de matéria seca, proteína bruta e energia bruta de 82,$9 ; 97,0$ e $82,6 \%$, respectivamente. Estes resultados foram favorecidos pela grande quantidade de folhas e caules pouco lignificados, com concentração de lignina de $7,4 \%$, o que possivelmente resultou nos coeficientes de digestibilidade superiores aos das demais leguminosas. Segundo Pedreira \& Consentino (1992), o macrotiloma é aceito por ruminantes e, até o momento, não existem relatos quanto ao consumo desta leguminosa pelos eqüinos. 
Os coeficientes de digestibilidade da MS, MO e EB do coastcross foram de 52,4;52,8 e 48,7\%, respectivamente, semelhantes aos observados por Almeida et al. (1999), de 49,$8 ; 50,5$ e $47,9 \%$, utilizando a técnica de coleta total de fezes em eqüinos. Valor de digestibilidade da proteína bruta inferior ao deste trabalho $(69,8 \%)$ foi observado por Almeida et al. (1999), de 56,1\%. Aiken et al. (1989) da mesma forma, em ensaio de digestibilidade com coleta total de fezes em eqüinos, observaram a digestibilidade da $\mathrm{PB}$ do feno de capim bermuda de $50,7 \%$, assim, a técnica dos sacos de náilon móveis pode ter superestimado a digestibilidade da proteína bruta.

Os constituintes do feno de coastcross que compõem a fração fibrosa, FDN e FDA, apresentaram digestibilidade de 47,5 e 39,4\%, respectivamente. Em comparação aos observados com a técnica de coleta total de fezes, esses valores foram similares, de 45,5 e 35,7\%, respectivamente (Aiken et al., 1989). No entanto, Almeida et al. (1999), utilizando a coleta total de fezes observaram valores de digestibilidade da FDN e FDA superiores, de $63,3 \%$ e $44,6 \%$, respectivamente.

Poucos trabalhos foram conduzidos com sacos móveis em eqüinos. Araújo et al. (2000) avaliaram a digestibilidade do feno de coastcross em eqüinos utilizando sacos de náilon móveis e amostras com três graus de moagem, de 1 , 3 e $5 \mathrm{~mm}$ e compararam aos valores de digestibilidade obtidos com a coleta total de fezes e verificaram que a digestibilidade da proteína bruta do capim coastcross moído a $1 \mathrm{~mm}$ foi de $68,2 \%$. No entanto, os coeficientes de digestibilidade de FDN e FDA foram superiores e próximos dos valores de digestibilidade observados por Aiken et al. (1989) e Almeida et al. (1999) com a coleta total de fezes. Provavelmente, as divergências nas estimativas dos coeficientes de digestibilidade de FDN e FDA observadas neste trabalho em relação aos resultados obtidos por Araújo et al. (2000) estão relacionadas às diferenças na maturidade da planta.

$\mathrm{O}$ amendoim forrageiro, estilosantes e o macrotiloma apresentaram elevada digestibilidade da proteína bruta ( $\mathrm{P}<0,05$ ), com valores de 97,0; 94,9 e 91,3\%, possivelmente por terem apresentado menores conteúdos de FDN, de 46,$8 ; 47,5$ e $38,2 \%$, respectivamente, possibilitando maior conteúdo de nutrientes solúveis na composição das forrageiras, representados principalmente pelos carboidratos não-fibrosos. De acordo com Almeida et al. (2007), os carboidratos não-fibrosos são também classificados como hidrolisáveis e rapidamente fermentáveis e representam 25; 24,6 e $35 \%$ da matéria seca do amendoim forrageiro, estilosantes e do macrotiloma, respectivamente.

O coeficiente de digestibilidade da FDA dos alimentos volumosos em eqüinos, considerando gramíneas e leguminosas, varia de 35 a $45 \%$ e depende principalmente do nível de lignificação da planta (Pagan, 2001). Entretanto, neste estudo os valores de digestibilidade da FDA nas leguminosas amendoim forrageiro, macrotiloma e estilosantes foram valores superiores, 70,9; 59,4 e 53,5\%, respectivamente. Os elevados coeficientes de digestibilidade da FDA estimados para estes alimentos podem estar relacionados principalmente à perda de partículas pela técnica dos sacos móveis. Estas forrageiras eram menos grosseiras e, ao serem moídas, o tamanho de partícula tornou-se menos uniforme, superestimando a digestibilidade da fibra em detergente ácido.

A perda de partículas de alimentos dos sacos está diretamente ligada à abertura do poro, uma característica importante no aspecto quantitativo da técnica, pois deve permitir apenas o influxo da microbiota, de enzimas digestivas e soluções tamponantes e, impedir a saída da amostra não-degradada (Huntington \& Givens, 1995). A perda de partículas de alimentos dos sacos também foi discutida por Hyslop (2006), que sugeriu que parte desse material não é necessariamente digerida, pois dissolve-se em solução e sai do saco antes mesmo de sua digestão. É importante impedir a entrada de material de origem dietética prevenindo valores subestimados de digestibilidade, bem como a saída precoce de material não digerido, o que leva à superestimativa dos coeficientes.

A técnica dos sacos móveis estimou satisfatoriamente os coeficientes de digestibilidade da matéria seca e apresentou vantagens experimentais, pois foram avaliados diversos alimentos em um único ensaio, reduzindo o tempo experimental. Contudo, é necessária a padronização da técnica principalmente quanto ao grau de moagem e lavagem dos sacos, a fim de não superestimar os coeficientes de digestibilidade.

As leguminosas amendoim forrageiro, macrotiloma e estilosantes, como conseqüência de seus coeficientes de digestibilidade e do valor nutricional, apresentaram potencial para o uso em dietas de eqüinos. Novos estudos serão necessários para avaliar o consumo voluntário das forrageiras na espécie eqüina.

\section{Conclusões}

O amendoim forrageiro (Arachis pintoi cv. Amarillo), o estilosantes (Stylosanthes guianensis cv. Mineirão) e o macrotiloma (Macrotyloma axillare) apresentam digestibilidade satisfatória dos nutrientes e possuem potencial para uso em dietas de eqüinos. A técnica dos sacos de náilon móveis é aplicável para estimativa da digestibilidade dos nutrientes em eqüinos. 


\section{Literatura Citada}

AIKEN, G.E.; POTTER, G.D.; CONRAD, B.E. et al. E. Voluntary intake and digestion of coastal Bermuda grass hay by yearling and mature horses. Journal of Equine Veterinary Science, v.9, n.5, p.262-264, 1989.

AlCÂNTARA, P.B.; BUfARAH, G. Plantas forrageiras: gramíneas e leguminosas. São Paulo: Nobel, 1988. 162p.

ALMEIDA, F.Q.; MORGADO, E.S.; SILVA, V.P. et al. Digestão dos carboidratos de alimentos volumosos para eqüinos. In: REUNIÃO ANUAL DA SOCIEDADE BRASILEIRA DE ZOOTECNIA, 44., 2007, Jaboticabal. Anais... Jaboticabal: Sociedade Brasileira de Zootecnia, 2007. (CD-ROM).

ALMEIDA, M.I.V. Predição da energia digestível de dietas para eqüinos a partir de seu conteúdo fibroso. 1994. $110 \mathrm{f}$. Dissertação (Mestrado em Zootecnia) - Universidade Federal de Minas Gerais, Belo Horizonte, 1994.

ALMEIDA, M.I.V.; FERREIRA, W.M.; ALMEIDA, F.Q. et al. Valor nutritivo do capim-elefante (Penninsetum purpureum, Schum), do feno de alfafa (Medicago sativa, L.) e do feno de capim coast-cross (Cynodon dactilon, L.) para eqüinos. Revista Brasileira de Zootecnia, v.28, n.4, p.743-752, 1999.

ANDRADE, I.F. Produção e composição química de leguminosas forrageiras tropicais cultivadas no cerrado. Revista da Sociedade Brasileira de Zootecnia, v.10, n.1, p.103-122, 1981.

ARAÚJO, K.V.; LIMA, J.A.F.; TEIXEIRA, J.C. et al. Determinação da digestibilidade aparente dos nutrientes de alguns concentrados e volumosos para eqüinos, pela técnica do saco de náilon móvel. Revista Brasileira de Zootecnia, v.25, n.5, p.945-956, 1996a.

ARAÚJO, K.V.; LIMA, J.A.F.; TEIXEIRA, J.C. et al. Uso da técnica do saco de náilon móvel na determinação da digestibilidade aparente dos nutrientes em eqüinos. Revista Brasileira de Zootecnia, v.25, n.5, p.957-963, 1996b.

ARAÚJO, K.V.; LIMA, J.A.F.; FIALHO, E.T. et al. Comparação da técnica do saco de náilon móvel com o método de coleta total para determinar a digestibilidade dos nutrientes de alimentos volumosos em eqüinos. Revista Brasileira de Zootecnia, v.29, n.3, p.752-761, 2000.

CUNHA, T.J. Horse feeding and nutrition. 2.ed. New York: Academic Press, 1980. 445p.

DAll'AGNOL, M.; SCHEFFER-BASSO, S.M. Utilização de recursos genéticos de leguminosas para ruminantes. In: REUNIÃO ANUAL DA SOCIEDADE BRASILEIRA DE ZOOTECNIA, 41., 2004, Campo Grande, Anais... Campo Grande: Sociedade Brasileira de Zootecnia, 2004, p.115-128.

FERREIRA, S.C.; GONÇALVES, L.C.; REZENDE, A.S.C. et al. Avaliação do consumo e da digestibilidade do capim elefante (Pennisetum purpureum) picado e do feno de guandu (Cajanus cajan) desintegrado em eqüinos. Arquivo Brasileiro de Medicina Veterinária e Zootecnia, v.47, n.2, p.239-248, 1995.

FUKUSHIMA, R.S. Otimização de método analítico para a determinação do teor de lignina. In: AVANÇOS EM TÉCNICAS DE PESQUISA EM NUTRIÇÃO DE RUMINANTES, 2007, Pirassununga. Anais... Pirassununga: Universidade de São Paulo, 2007. p.254-279.

HUNTINGTON, J.A.; GIVENS, D.L. The in situ technique for studying the rumen degradation of feeds: a review of the procedure. Nutrition Abstracts and Reviews (Series B), v.65, n.2, p.63-93, 1995.

HYSLOP, J.J. In situ and mobile bag methodology to measure the degradation profile of processed feeds in different segments of the equine digestive tract. Livestock Production Science, v. 100, p. $18-32,2006$.

JUNG, H.G.; FAHEY JR., G.C. Influence of phenolic acids on forage structural carbohydrate digestion. Canadian Journal of Animal Science, v.64, p.50-51, 1984.
JUNG, H.G.; ALLEN, M.S. Characteristics of plant cell walls affecting intake and digestibility of forages by ruminants, Journal of Animal Science, v.73, p.2774-2790, 1995.

LADEIRA, M.M.; RODRIGUEZ, N.M.; BORGES, I. et al. Avaliação do feno de Arachis pintoi utilizando o ensaio de digestibilidade in vivo. Revista Brasileira de Zootecnia, v.31, n.6, p.23502356, 2002a.

LADEIRA, M.M.; RODRIGUEZ, N.M.; BORGES, I. et al. Balanço de nitrogênio, degradabilidade de aminoácidos e concentração de ácidos graxos voláteis no rúmen de ovinos alimentados com feno de Stylosanthes guianensis. Revista Brasileira Zootecnia, v.31, n.6, p.2357-2363, 2002b.

MACHEBOEUF, D.; PONCET, C.; JESTIN, M. et al. Mobile nylon bag technique (MNBT) in caecum fistulated horses as an alternative method for estimating precaecal and total tract nitrogen digestibilities of feedstuffs. In: EQUINE NUTRITION AND PHYSIOLOGY SOCIETY SYMPOSIUM, 18., 2003, Michigan. Proceedings... Michigan: Equine Nutrition Physiology Society Symposium, 2003. p.347-351.

MANZANO, A.; MANZANO, M.F.F.L. Utilização do guandu (Cajanus cajan (L) Millsp) na alimentação de eqüinos. Revista da Sociedade Brasileira de Zootecnia, v.19, n.6, p.459469, 1990 .

MOORE-COLYER, M.J.S.; HYSLOP, J.J.; LONGAND, A.C. et al. Degradation of four dietary fiber sources by ponies as measured by ponies as measured by the mobile bag technique. In: EQUINE NUTRITION AND PHYSIOLOGY SOCIETY SYMPOSIUM, 18., 2003, Michigan. Proceedings... Michigan: Equine Nutrition Physiology Society Symposium, 2003. p.153-154.

MOORE-COLYER, M.J.S.; HYSLOP, J.J.; LONGLAND, A.C. et al The mobile bag technique as a method for determining the degradation of four botanically diverse fibrous feedstuffs in the small intestine and total digestive tract of ponies. British Journal of Nutrition, v.88, p.729-740, 2002.

NATIONAL RESEARCH COUNCIL - NRC. Nutrient requirements of horses. 5.ed. Washington, D.C.: National Academy Press, 1989. $100 \mathrm{p}$.

NATIONAL RESEARCH COUNCIL - NRC. Nutrient requirements of horses. 6.ed. Washington, D.C.: National Academy Press, 2007. $341 \mathrm{p}$.

PÁDUA, F.T.; ALMEIDA, J.C.C.; SILVA, T.O. et al. Produção de matéria seca e composição químico-bromatológica do feno de três leguminosas forrageiras tropicais em dois sistemas de cultivo. Ciência Rural, v.36, n.4, p.1253-1257, 2006.

PAGAN, J.D. Forages for horses: more than just filler. In: PAGAN, J.D. (Ed.) Advances on equine nutrition I. Versailles: Kentucky Equine Research, 2001. p.13-28.

PEDREIRA, J.V.S.; COSENTINO, J.R. Avaliação de leguminosas forrageiras sob condições de várzea parcialmente drenada. Boletim da Indústria Animal, v.49, n.1, p.55-61, 1992.

PEIXOTO, M.A.; PEDREIRA, C.G.S.; MOURA, J.C. et al. A planta forrageira no Sistema de Produção. In: SIMPÓSIO SOBRE MANEJO DA PASTAGEM, 17., 2000, Piracicaba. Anais... Piracicaba: Escola Superior de Agricultura Luiz de Queiroz, 2000. p.1-393.

PEREIRA, J.C.; QUEIROZ, A.C.; CARMO, M.B. Avaliação de métodos para determinação da digestibilidade aparente em eqüinos. Revista Brasileira de Zootecnia, v.24, p.382-390, 1995.

SAUER, W.C.; JORGENSEN, H.; BERZINS, R. A modified naylon bag technique for determining apparent digestibilities of protein in feedstuffs for pigs. Canadian Journal of Animal Science, v.63, n.1, p.233-237, 1983.

SILVA, D.J.; QUEIROZ, A.C. Análise de alimentos: métodos químicos e biológicos. 3.ed. Viçosa, MG: Editora UFV, 2002. 235p.

TODD, L.K.; SAUER, W.C.; CHRISTOPHERSON, R.J. et al. The effect of feeding different forms of alfafa on nutrient digestibility and voluntary intake in horses. Journal of Animal Physiology and Animal Nutrition, v.73, p.1-8, 1995. 
UNIVERSIDADE FEDERAL DE VIÇOSA - UFV. SAEG - Sistema de análises estatísticas e genéticas (versão 8.0). Viçosa, MG: Universidade Federal de Viçosa, 2000. 150p. (Manual do usuário).

VALADARES FILHO, S.C.; MAGALHÃES, K.A.; ROCHA JR., V.R. et al. Tabelas brasileiras de composição de alimentos para bovinos. 2.ed. Viçosa, MG: Universidade Federal de Viçosa, 2006. 300p.

VANZANT, E.S.; COCHRAN, R.C.; TITGEMEYER, E.C. Standardization of in situ techniques for ruminant feedstuff evaluation. Journal of Animal Science, v.76, p.2717-2729, 1998. 